\title{
Ambient Particulate Matter Affects Cardiac Recovery in a Langendorff Ischemia Model
}

\section{Karim Bagate ${ }^{1,2}$, James J. Meiring ${ }^{1}$, Miriam E. Gerlofs-Nijland ${ }^{3}$, Flemming R. Cassee ${ }^{3}$, Herbert Wiegand ${ }^{1}$, Alvaro Osornio-Vargas ${ }^{4}$ and Paul J. A. Borm*1, 5}

${ }^{1}$ Particle Research, Institut fur Umweltmedizinische Forschung (IUF gGmhH) at the University of Düsseldorf, NRW, Germany.

${ }^{2}$ Faculty of Natural Sciences, University of Abobo-Adajmé, Abidjan, Côte d'Ivoire.

${ }^{3}$ Center for Environmental Health Research, National Institute for Public Health and the Environment (RIVM), Bilthoven, The Netherlands.

${ }^{4}$ Instituto Nacional de Cancerología, Mexico City, Mexico.

${ }^{5}$ Center of Expertise, Life Sciences, Heerlen, The Netherlands.

Received: November 27, 2005; Accepted: March 24, 2006

*Correspondence: Paul J. A. Borm, Zuyd University, Center of Expertise, Life Sciences, Heerlen, PO Box 300, 6400, AN, The Netherlands; E-mail: p.borm@hszuyd.nl

Exposure to ambient particulate matter (PM) is associated with increased mortality and morbidity among subjects with cardiovascular impairment. We hypothesized that exposure of spontaneously hypertensive (SH) rats to PM impairs the recovery of cardiovascular performance after coronary occlusion and reperfusion-ischemia. SH rats were exposed by intratracheal instillation to saline, standard urban PM (Ottawa dust EHC-93, $10 \mathrm{mg} / \mathrm{kg}$ body weight) or endotoxin (lipopolysaccharides LPS, $350 \mathrm{EU} / a n i m a l)$ to induce a similar pulmonary inflammation. At $4 \mathrm{~h}$ postexposure, hearts were isolated and retrograde perfused in a Langendorff model. The experimental protocol included 35 min of coronary occlusion followed by 120 min of reperfusion, during which left ventricular developing pressure (LDVP), coronary flow (CF), and heart rate (HR) were measured. Baseline LVDP in particle-instilled $\mathrm{SH}$ rats was significantly decreased compared to saline-instilled animals. In addition, after ischemia the recovery of LDVP was much slower in rats pretreated with PM or LPS compared to saline instilled rats. The direct effects of the soluble PM fraction and the role of $\mathrm{Zn}^{2+}$ were also tested cardiomyocytes ( $\mathrm{H} 9 \mathrm{C} 2$ cells). Both particle-free filtrate and $\mathrm{Zn}^{2+}$ inhibited ATP or ionophore-stimulated calcium influx in cardiomyocytes. This inhibitory effect was related to an effect on calcium channels, as shown with Nifedipine. This study provides evidence that exposure to instillation of PM has reversible acute effects on the recovery of cardiac physiological parameters after ischemia. The effect may be caused by a direct action of soluble metals on calcium homeostasis in heart, but pulmonary inflammation may also play a significant role.

Epidemiological studies have demonstrated a relationship between exposure to ambient particulate matter (PM) and adverse effects in subpopulations with cardiopulmonary diseases. A positive correlation between increase in air pollution and cardiopulmonary-related morbidity and mortality has been reported in various studies (Pope et al., 2004; Dockery et al., 1993; Peters et al., 2004). Both direct and indirect effects of particles or their constituents have been suggested to explain this effect. Experimental and panel studies have indicated that PM can cause a direct increase in systolic blood pressure and altered autonomic nervous system control of cardiac rhythm (Ibald-Mulli et al., 2001), 
leading to change in heart-rate variability (Godleski et al., 2000; Pope et al., 1999; Gold et al., 2000) and increase in heart rate (Peters et al., 1999) and an increased risk for myocardial insult within $2 \mathrm{~h}$ after exposure (Peters et al., 2004).

Seaton et al. (1995) were the first to suggest an indirect effect through pulmonary inflammation caused by particle deposition leading to increased blood coagulability and plasma viscosity, thus indirectly promoting myocardial infarction. Such indirect effects may be mediated by the release of cytokines such as interleukin (IL)- 1 and IL- 6 from the lung into the systemic circulation (Van Eeden et al., 2001). Residual oil fly ashes (ROFA) have been reported to induce COX-2 expression and release of $\mathrm{PGE}_{2}$ from lung epithelial cells (Samet et al., 2000). PM also caused the release of endothelin from the lung to the blood (Bouthilier et al., 1998). Endothelin is well known to be involved in congestive heart failure, hypertension, vascular remodeling from arteriosclerosis, postangioplastic restenosis, and asthma (Vincent et al., 2001). In addition, histamine has been shown to mediate diesel particle-induced peripheral thrombosis via $\mathrm{H}_{1}$ receptor activation, since a specific antagonist was able to block this effect (Nemmar et al., 2003). We recently demonstrated in isolated perfused lung that the translocation of ultrafine particles is enhanced upon administration of histamine on the endothelial side or hydrogen peroxide on the luminal side (Meiring et al., 2005).

However, much less is known about the mechanisms by which PM and its constituents affect cardiovascular performance. A disturbance of vascular function elicited by PM has been reported by our group (Bagate et al., 2004a, 2004b; Knaapen et al., 2001) as well as others (Batalha et al., 2002; Brook et al., 2002; Mills et al., 2005; Nurkiewicz et al., 2006). This suggests that if sufficient particles or their soluble constituents are translocated upon inhalation and reach the blood they are capable of inducing direct effects on the cardiovascular system. In-vitro studies with diesel exhaust particles (DEP) showed negative inotropic and positive chronotropic effects followed by cardiac arrest (Sakakibara et al., 1994) in guinea pig isolated cardiac muscle preparations. Intravenous administration of DEP in guinea pigs induced arrhythmia and death by atrioventricular block (Minami et al., 1999). We hypothesized that exposure to PM, apart from exerting a direct effect on the lung and heart, could also impair recovery of of the heart after ischemic insult. Such an effect would only become visible after substantial damage such as after coronary occlusion and reperfusionischemia, as seen in survivors of myocardial infarction (MI). In other words, the effects of PM on mortality may not be caused by causing MI but by a slower recovery from small or larger myocardial infarctions. To test this hypothesis we subjected isolated hearts from spontaneously hypertensive (SH) rats, after in vivo exposure to PM, to ischemia by coronary occlusion, and we studied functional recovery and pathological damage during reperfusion. Ischemia-reperfusion insult has been extensively studied for its clinical relevance, and the Langendorff model with the retrograde perfusion is the standard ex vivo technique that is used for experimental work (e.g., Xu et al., 2003). To elucidate the role of pulmonary inflammation in the effect of PM, SH rats were treated by intratracheal instillation with standard urban PM 10 (EHC-93) and compared to endotoxin (LPS)- and saline-instilled animals. At $4 \mathrm{~h}$ postexposure, hearts were isolated and retrograde perfused in the Langendorff model. The central aim of our study was to investigate the effect of PM exposure on physiological performance of the heart in an ischemic/reperfusion model.

\section{METHODS}




\section{Animals}

Male spontaneously hypertensive rats (SHR/NHsd) of 11-12 wk old and weighing 250-350 g were obtained from the breeding colony of Harlan (Indianapolis, IN). Immediately after arrival, the animals were weighed and randomly allocated. Animals were housed in macrolon cages Type 3, in a room at constant climate with a 12-h light/dark cycle (light on at 8 a.m.) and allowed free access to an automatic drinking water system and SSP-Tox standard food (Hope Farms, Woerden, the Netherlands). Basic inspection of animals took place every day. The Ethical Review Committee of the National Institute for Public Health and the Environment (RIVM) approved experiments. The animals were instilled with particles (EHC-93, $10 \mathrm{mg} / \mathrm{kg}$ of body weight in a concentration of $5 \mathrm{mg} / \mathrm{ml}$ ), LPS (350 endotoxin units/animal, $0.5 \mathrm{ml}$ ), or saline $(2 \mathrm{ml} / \mathrm{kg}$ of body weight) through a cannula inserted into the trachea just above the bifurcation. Before this manipulation animals were briefly anesthetized by $4 \%$ halothane inhalation.

\section{Chemicals and Particles}

Lipopolyssacharide (LPS) was obtained from Sigma-Aldrich (Chemie Gmbh); ketamine from Aesculap (Boxtel, the Netherlands), rompun from Bayer AG (Leverkusen), and PM (EHC-93) from the Health Effects Institute (Ottawa, Canada). All other chemicals were of pro-analysis quality from Merck (Darmstadt, Germany). Compounds were dissolved in double-distilled water and freshly prepared with saline before each experiment. For in vivo instillations we used urban PM (EHC-93) that was collected in Ottawa (Canada) in 1993. Lipopolyssacharide (LPS) content of EHC-93 was determined using the Limulus amebocyte lysate (LAL) assay as described previously (Schins et al., 2004). A suspension of EHC-93 particles was obtained by suspending EHC-93 in saline at the desired concentration by sonication.

For details on particle size and composition we refer to previous publications (Bagate et al., 2004a; Gerlofs-Nyland et al., 2005). For in vitro perfusions we used zinc sulfate, since zinc is the major soluble metal in the PM sample that was used. All the in vitro experiments were done with the soluble fraction of EHC-93 or solutions of metals. The soluble fraction was prepared from the EHC-93 suspension, by filtering with a syringe mounted on a $0.1-\mu \mathrm{m}$ filter (Minisart RC15, Sartorius AG, Göttingen-Germany). This procedure was shown not to affect the concentration of active soluble metals such as zinc, copper, magnesium, and vanadium in the filtrates (data not shown).

\section{Isolation of Hearts and Experimental Protocol}

Necropsy took place at $4 \mathrm{~h}$ after instillation of PM, LPS, or saline. Animals were anesthetized with an ip injection ( $1 \mathrm{ml} / \mathrm{kg}$ of body weight) of a mixture of ketamine $(100 \mathrm{mg} / \mathrm{ml})$ and rompun $(20 \mathrm{mg} / \mathrm{ml})$ in a ratio of $10: 4$. A pilot study comparing the effect of this procedure on rats receiving no PM or LPS but killed by decapitation showed no significant effect on the heart function (data not shown). After opening the thorax, a syringe containing a cold Krebs-Ringer (KR) solution $\left(4^{\circ} \mathrm{C}\right)$ was inserted in the aorta through a canula. The heart was rapidly excised and immediately suspended for retrograde perfusion (Langendorff model) with pre-warmed $\left(37^{\circ} \mathrm{C}\right)$ and oxygenated $\left(95 \% \mathrm{O}_{2} / 5 \% \mathrm{CO}_{2}\right)$ modified $\mathrm{KR}$ solution at $60 \mathrm{~mm} \mathrm{Hg}$ constant pressure with the following composition $(\mathrm{mM}): \mathrm{NaCl} 118$; $\mathrm{KCl} 5.9 ; \mathrm{CaCl}_{2} 2.5 ; \mathrm{MgSO}_{4} 1.2 ; \mathrm{NaH}_{2} \mathrm{PO}_{4} 1.2 ; \mathrm{NaHCO}_{3} 24.9 ;$ glucose $11.1 ; \mathrm{pH}$ was adjusted to 7.4. The left ventricular developed pressure (LVDP) was measured via a water-filled balloon inserted into the left ventricle and connected via a catheter with a disposable transducer (Spectramed Becton-Dickinson). LVDP and heart rate (HR) were recorded on a Graphtec linear recorder Mark 8, type WR 3500 (Hugo Sacks Electronic, Germany) equipped with differentiator amplifiers (DC bridge amplifier DBA 660, Hugo Sachs Electronic, Germany) and a heart-rate module (HRM 669, Hugo Sachs Electronic, Germany). The $(d P / d t)_{\max }$ (velocity of 
contraction) was calculated from the recorded parameters. Diastolic ventricular pressure was adjusted to between 5 and $10 \mathrm{~mm} \mathrm{Hg}$. Coronary flow was established by measuring the volume of perfusate leaving the coronary system. Basal flow was between 8 and $10 \mathrm{ml} / \mathrm{min}$. The experimental procedure for ischemia and recovery was established as follows. First, all the hearts were equilibrated for $30 \mathrm{~min}$. An ischemic period of $35 \mathrm{~min}$ was induced by coronary artery occlusion. Subsequently a reperfusion period of $120 \mathrm{~min}$ was allowed for all groups. Other experiments on isolated hearts were done without previous ischemia and done on hearts of $\mathrm{SH}$ rats pretreated with saline. In these experiments the effects of the water-soluble fraction of PM or a solution of $\mathrm{Zn}^{2+}$, as major metal present in our particle preparations, were tested by a $10 \mathrm{~min}$ of infusion. A similar equilibration period for isolated hearts was applied before infusion of test solutions.

\section{Pathological Examination of the Hearts After Perfusion}

Hematoxylin-eosin stained sections ( $5 \mu$ m thick) were evaluated using fluorescence microscopy (Olympus BX40, filter set WIB) to identify early ischemic versus normal regions of the heart by their autofluorescence pattern (Osornios \& Ossa Gómez, 1993). Autofluorescence was evaluated in blind manner without knowing the experimental conditions that the rats were subjected to. Ischemic regions were reported for the right and left ventricle (free wall and septum) accordingly for subendocardial, subepicardial, or transmural location. The extension of the ischemic areas was estimated as a percentage of the histological section affected and reported as: $0=$ no ischemia; $\pm=<5 \% ;+=6-20 \% ;++$ $=21-35 \% ;+++=36-50 \% ;++++=>50 \%$.

\section{Calcium Imaging in Cardiomyocytes}

Cardiomyocyte H9c2 cells were obtained from European cell collection (EACC). Cells were cultured in Dulbecco's modified essential medium supplemented with $10 \%$ fetal bovine serum, $2 \mathrm{mM}$ glutamine, $100 \mathrm{U} / \mathrm{ml}$ penicillin, $100 \mathrm{mg} / \mathrm{ml}$ streptomycin, and $1 \mathrm{mM}$ pyruvate in humidified air $\left(\mathrm{CO}_{2} 5 \%\right)$ at $37^{\circ} \mathrm{C}$. For imaging experiments, cells were plated onto poly-D-lysine-coated glass cover slips. Cells were grown for 3-5 days to subconfluent cultures. Prior to loading with fluorescent dyes, cells were preincubated for $30 \mathrm{~min}$ with medium ( $2 \%$ bovine serum albumin/extracellular medium) consisting of $121 \mathrm{mM} \mathrm{NaCl}, 5 \mathrm{mM} \mathrm{NaHCO}$, $10 \mathrm{mM} \mathrm{Na}$-HEPES, $4.7 \mathrm{mM} \mathrm{KCl}, 1.2 \mathrm{mM} \mathrm{KH} \mathrm{PO}_{4}, 1.2 \mathrm{mM} \mathrm{MgSO}{ }_{4}, 2 \mathrm{mM} \mathrm{CaCl}, 10$ $\mathrm{mM}$ glucose, and $2 \%$ bovine serum albumin, $\mathrm{pH} 7.4$, at $37^{\circ} \mathrm{C}$ (Pacher et al., 2000, 2001; Szalai et al., 2000). To measure intracellular calcium, $[\mathrm{Ca}]_{i}$, cells grown on glass cover slips were washed twice with Hanks balanced salt solution (HBSS) and incubated in HBSS, pH 7.3, containing $1 \mu \mathrm{M}$ Fura-2/AM for 30 min at $37^{\circ} \mathrm{C}$. Following incubation the cells were washed twice with $4 \mathrm{ml}$ Fura-2/AM free HBSS and mounted on an inverted microscope (Zeiss Axiovert, Germany) and washed for another $5 \mathrm{~min}$ to remove excess of Fura-2/AM. Fluorescence of six to eight cells was simultaneously monitored using digital imaging fluorescence microscopy (Photon Technology International, Birmingham, NJ) as described earlier (Bickmeyer et al., 1998). Briefly, the images were obtained through an oil immersion objective $(40 \times)$ and visualized with a high-sensitivity camera (SIMICCD-04). Fluorescence ratios were obtained from the two background-corrected images at 340 and $380 \mathrm{~nm}$ excitation and $510 \mathrm{~nm}$ emission wavelengths. In calibration experiments we used HBSS containing $10 \mu \mathrm{M}$ ionomycin and $10 \mu \mathrm{M}$ gramicidin in the presence of $10 \mathrm{mM} \mathrm{CaCl} 2$ (R-max) and without calcium but with $1 \mathrm{mM}$ EGTA (R-min). Cell autofluorescence was determined in $10 \mathrm{mM}$ manganese chloride. Experiments were carried out with the soluble fraction of PM or $\mathrm{Zn}{ }^{2+}$ solutions evaluating at least 7 to 12 different cells per run, and a total of 35-100 cells per experiment. For calcium influx, cells were challenged with a depolarization solution $\mathrm{KCl}(50 \mathrm{mM})$ or receptor-dependent calcium influx and were established with ATP $(100 \mu M)$. Solutions were tested in two periods 
separated by a 30 -min interval. Particle-free filtrate $(1,50$, and $100 \mu \mathrm{g} / \mathrm{ml}$ final concentration) or $\mathrm{ZnSO}_{4}(50 \mu \mathrm{M})$ were applied during the 30-min interval in order to verify their ability to modify calcium influx in cardiomyocytes.

Cytotoxicity testing (MTT assay) revealed that neither PM nor Zn at at the applied concentrations led to cell death (data not shown). The effect of PM soluble components on intracellular calcium influx was evaluated with thapsigargin $(1 \mu$ $M)$, whereas their effect on extracellular calcium influx was tested with the calcium channel agonist dihydropyridine Bayk $8344(1,5$, and $10 \mu M)$. The results of each individual experiment were evaluated as the mean variation of the ratio $340 / 380 \mathrm{~nm}$, depicting the emissions at $510 \mathrm{~nm}$ using 340 or $380 \mathrm{~nm}$ excitation.

\section{Statistical Analysis}

Results are expressed as means \pm SEM. Differences were tested for statistical significance by the paired or unpaired Student's $t$-test and one-way or two-way variance analysis on repeated measurements when appropriate. Multiple comparisons between groups were performed by Tukey's test or the NewmanKeuls test. A $p$ value less than .05 was considered significant. All statistics were run with SPSS 9.0 for Windows.

\section{RESULTS}

\section{Effect of Pretreatment on Baseline Parameters of Isolated Perfused Heart}

The baseline performance of hearts taken from $\mathrm{SH}$ rats after exposure to $\mathrm{PM}$ or LPS in comparison to saline is shown in Table 1. The isolated hearts were allowed stabilization for 30 min before starting the recording of functional parameters. After PM exposure a slight increase of baseline coronary flow (CF) and heart rate (HR) was noted. In contrast, a significant decrease of LVDP was observed in SH rats $4 \mathrm{~h}$ after instillation. LPS also elicited a decrease of LVDP, but this change was not statistically significant. No pathological abnormalities were found in hearts up to 120 min of baseline perfusion (data not shown).

TABLE 1 Effect of particle and LPS instillation on physiological parameters during the reperfusion period of the isolated perfused heart

\section{Coronary flow $(\mathrm{ml} / \mathrm{min})$ Heart rate $(\mathrm{bpm})$}

\section{$\operatorname{LVDP}(\mathbf{m m ~ H g})$}

nSaline PM LPS Saline PM LPS Saline PM LPS

Note. Results are given as means \pm SEM of five individual experiments for each point. Statistical analysis was done by two-way ANOVA with repeated measures followed by a Student-Newman-Keuls test for multiple comparisons.

${ }^{a}$ Significant at $p<.05$ vs. saline.

${ }^{b}$ Significant at $p<.05$ versus baseline in the same group.

'Significant at $p<.01$ versus baseline in the same group.

\begin{tabular}{|c|c|c|c|c|c|c|c|}
\hline Baseline & $\begin{array}{c}59.8 \pm 1.6 \frac{10.8 \pm}{2.1}\end{array}$ & $\begin{array}{l}10.6 \pm \\
1.5\end{array}$ & $\begin{array}{l}246 \pm \\
15.4\end{array}$ & $\begin{array}{l}260 \pm \\
30.0\end{array}$ & $\begin{array}{l}275 \pm \\
20.0\end{array}$ & $115 \pm 7.9$ & $78 \pm 10.9^{a} 98 \pm 7.9$ \\
\hline $5 \mathrm{~min}$ & $57.9 \pm 1.0 \frac{10.2 \pm}{2.1}$ & $\begin{array}{l}7.7 \pm \\
1.55\end{array}$ & $\begin{array}{l}298 \pm \\
34.3\end{array}$ & $\begin{array}{l}273 \pm \\
14.0\end{array}$ & $\begin{array}{l}251 \pm \\
27.2\end{array}$ & $103 \pm 11$ & $\begin{array}{c}63.3 \pm 25^{a} 73.8 \pm \\
6.6^{a}\end{array}$ \\
\hline $60 \mathrm{~min}$ & $\begin{array}{r}55.8 \pm 0.9^{b} 9.9 \pm \\
2.5\end{array}$ & $\begin{array}{l}5.6 \pm \\
0.7^{b}\end{array}$ & $\begin{array}{l}304 \pm \\
25.0\end{array}$ & $\begin{array}{l}274 \pm \\
20.6\end{array}$ & $\begin{array}{l}248 \pm \\
32.6\end{array}$ & $\begin{array}{l}75.6^{ \pm} \\
10.3^{b}\end{array}$ & $\begin{array}{r}57.7 \pm 20^{a}, 53.2 \pm \\
8.1^{a},^{c}\end{array}$ \\
\hline $120 \mathrm{~min}$ & $\begin{array}{c}54.8 \pm 0.6^{c} 11.2 \pm \\
3.7^{a}\end{array}$ & $\begin{array}{l}4.5^{ \pm} \\
0.9^{b}\end{array}$ & $\begin{array}{l}242 \pm \\
18.5\end{array}$ & $\begin{array}{l}273 \pm \\
31.9\end{array}$ & $\begin{array}{l}242 \pm \\
10.7\end{array}$ & $72 \pm 9.0^{b}$ & $\begin{array}{ll}45 \pm & 39.4 \pm \\
13.1^{a}, b & 6.7^{a}, c\end{array}$ \\
\hline
\end{tabular}




\section{Effect of Pretreatment and Ischemia on Cardiac Function}

After the stabilization period, isolated hearts were subjected to ischemia during 35 min by arterial occlusion, and subsequent release of occlusion and normal retrograde perfusion during $120 \mathrm{~min}$. The physiological parameters were monitored during the whole interval. A significant difference in LVDP recovery was observed between the saline-treated rats and the rats exposed to PM or LPS (Figure 1). In control animals, an initial decrease to $50 \%$ of baseline value and restoration to $90 \%$ of the baseline value within $60 \mathrm{~min}$ after release were seen. After that, LDVP remained more or less constant during the rest of the perfusion period. When SH rats were pretreated with PM or LPS, the isolated heart had a clearly reduced ability to recover to baseline levels after occlusion in comparison with the saline-treated animals (Figure 1). LVDP was down to $50 \mathrm{~mm} \mathrm{Hg}$ in both cases after occlusion and remained at this level until the end of the reperfusion period. No significant effects of occlusion or exposure to PM and LPS were observed for heart rate, which remained constant at all time points and treatments (Table 1 ). A totally different response was noted for coronary flow. After releasing the occlusion, CF goes back to baseline values. Subsequently, both in saline- and LPS-treated rats a gradual decrease in CF was noted during the reperfusion period. On the other hand, isolated hearts from PM-exposed $\mathrm{SH}$ rats showed complete restoration of CF and no gradual decrease at all (Table 1). To test whether soluble metals are able to cause some effects on cardiac performance as observed after in-vivo PM pre-treatment, a Zn-containing solution was perfused in the heart through the perfusion solution at $0.1 \mathrm{ml} / \mathrm{min}$ to reach a final concentration of $10 \mu \mathrm{M}$ within $10 \mathrm{~min}$ (Figure 2). After that, $\mathrm{Zn}^{2+}$-free solution was added to the system, which allowed elimination of $\mathrm{Zn}^{2+}$ from the perfusion chamber. The infusion of $\mathrm{Zn}^{2+}$ elicited a rapid decrease of LVDP and heart rate (Figure 3$)$. The $(d P / d t)_{\max }$, calculated from the previous parameters, was also significantly reduced (data not shown). The impairment of cardiac function measured by LVDP and heart rate started immediately upon $\mathrm{Zn}^{2+}$ infusion and remains the same during the whole perfusion period, even though no $\mathrm{Zn}^{2+}$ was present in the perfusate (Figure 3a).

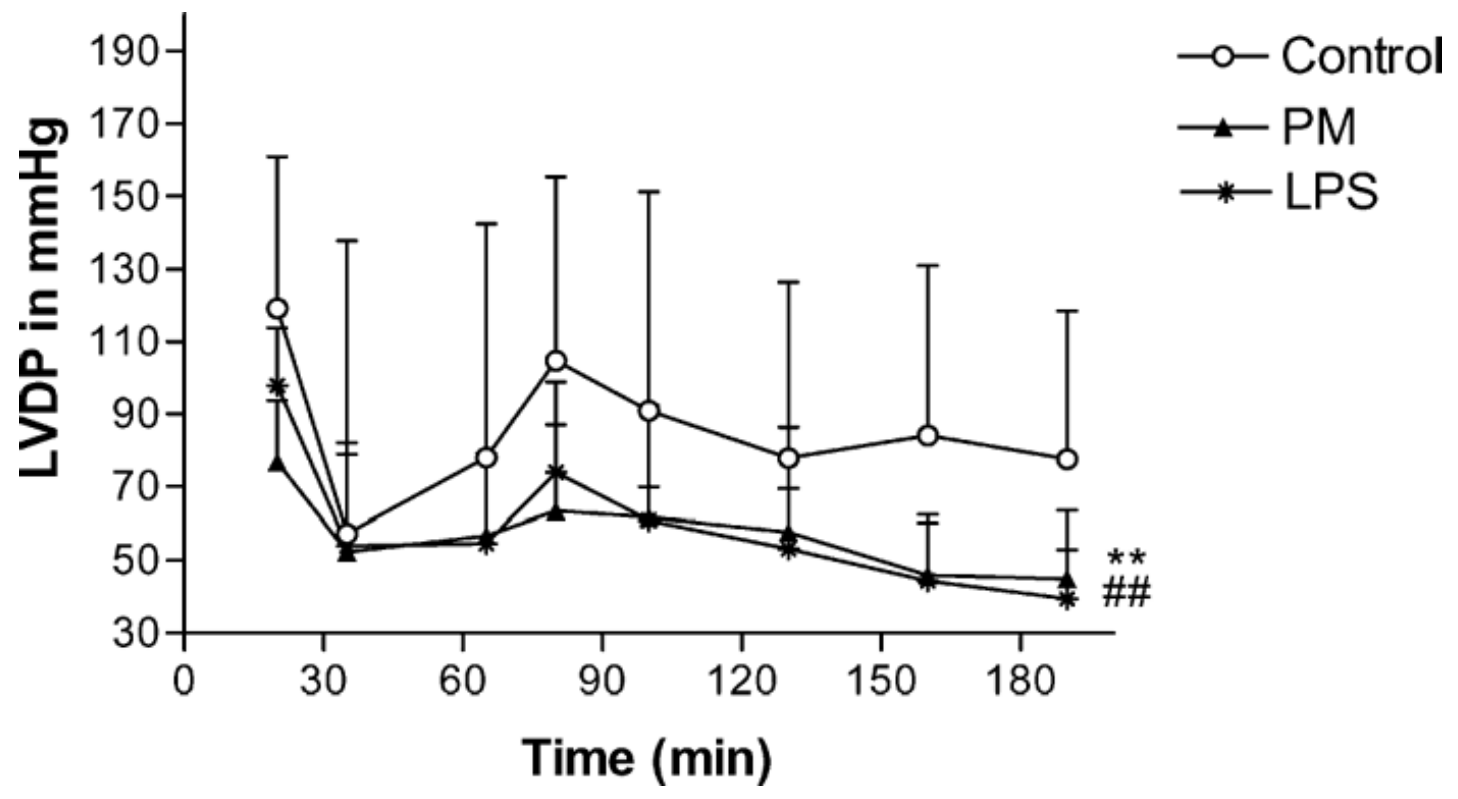

FIG. 1 Recovery of left ventricular developing pressure (LVDP) in isolated rat hearts is impaired in PM- and LPS-treated rats. Graphs shows time course of LDVP during and after 35-min occlusion of the coronary artery. Results are given as means \pm SEM of five individual experiments for each time point. Statistical 
analysis was done by one-way ANOVA with repeated measures followed by a Student-Newman-Keuls test for multiple comparisons. Symbols indicate significance, double asterisk and \#\#, $p<.01$ versus saline.

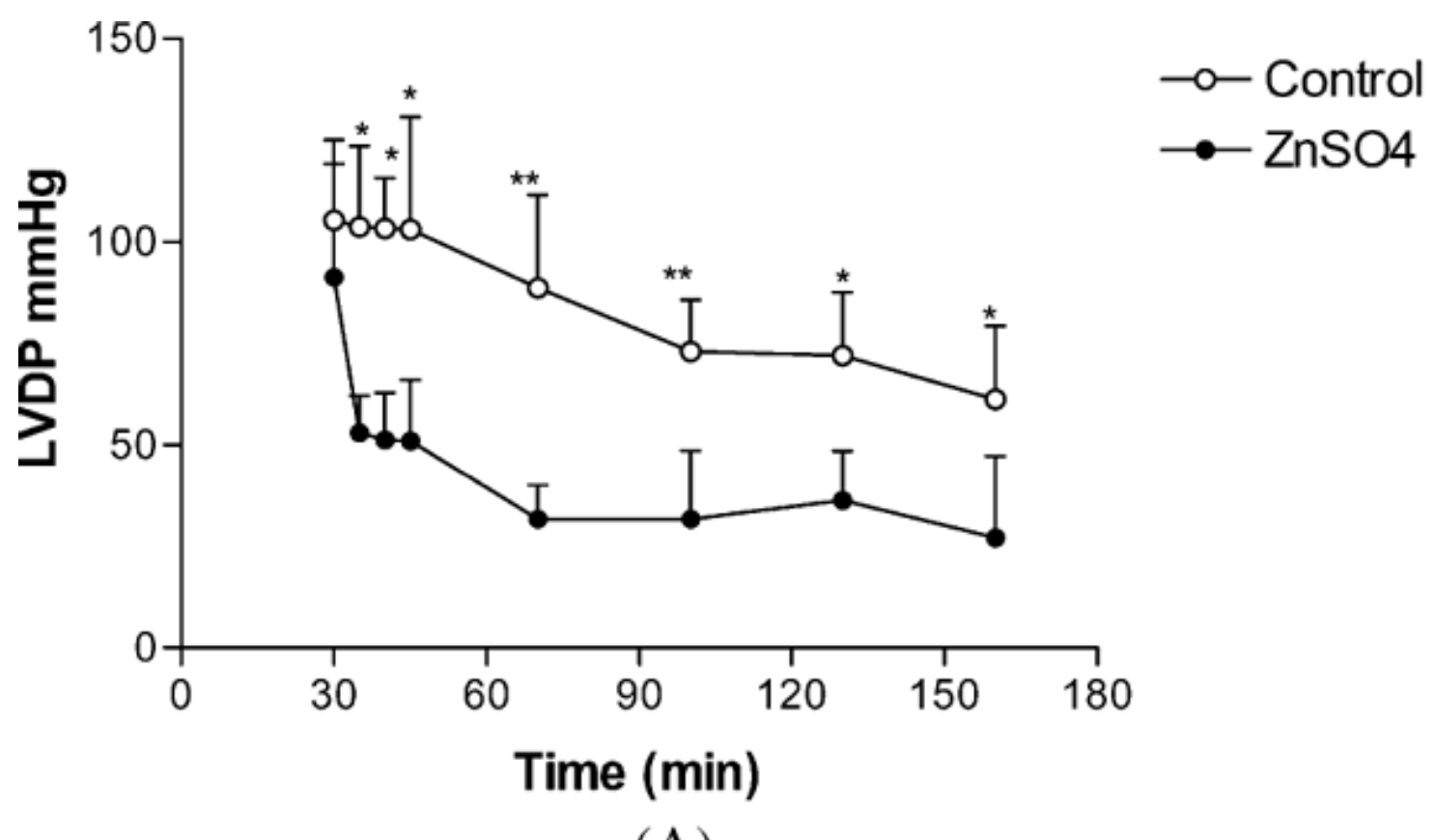

(A)

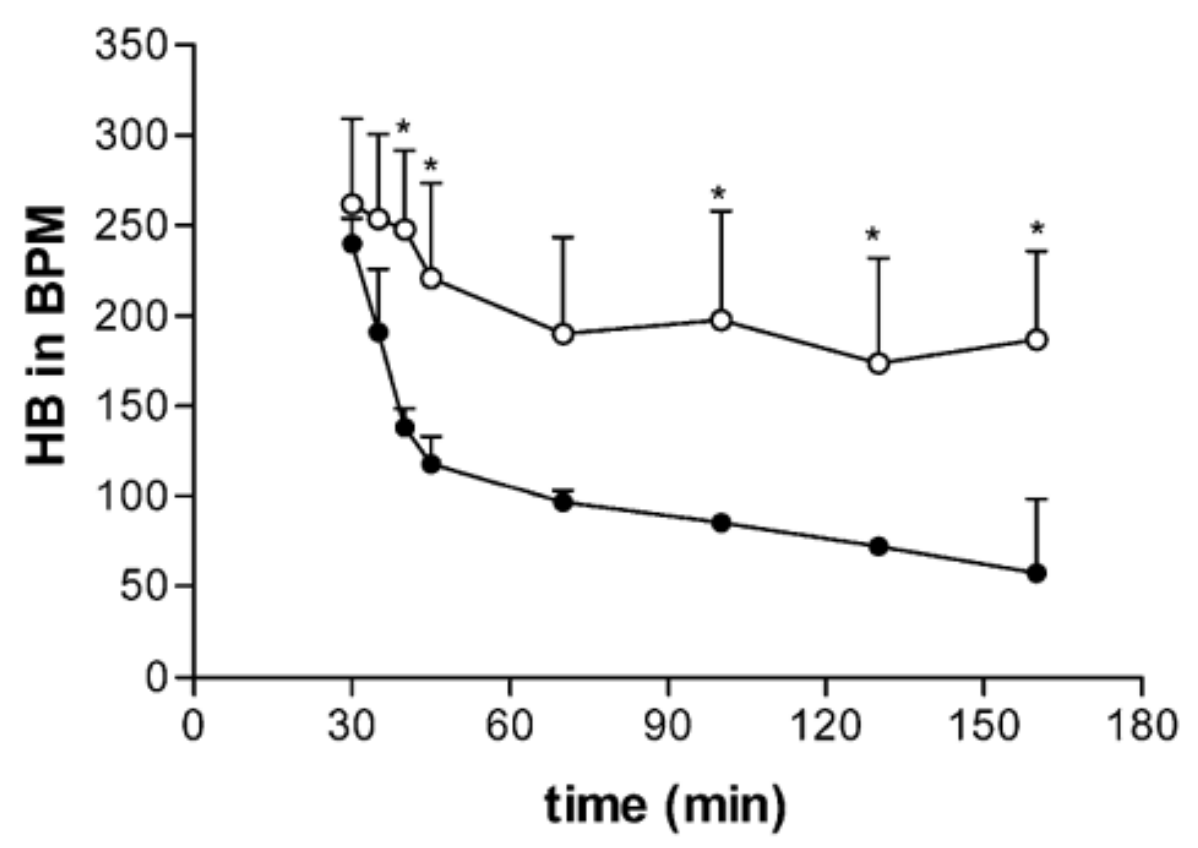

(B)

FIG. 2 Direct effect of infusion of $\mathrm{ZnSO}_{4}$ solution $(10 \mu \mathrm{M})$ negatively affects $(A)$ LDVP and (B) heart rate in isolated rat hearts. The $\mathrm{Zn}$ solution was infused into the heart during $10 \mathrm{~min}$ to reach a $10 \mu \mathrm{M}$ concentration in the medium, after which $\mathrm{Zn}$-free medium was supplied during the rest of the perfusion time. No occlusion was applied in this experiment. Results are given as means \pm SEM of 
five individual experiments for each point. Statistical analysis was done by oneway ANOVA with repeated measures followed by a Student-Newman-Keuls test for multiple comparisons. Asterisk indicates significant at $p<.05$ versus control.
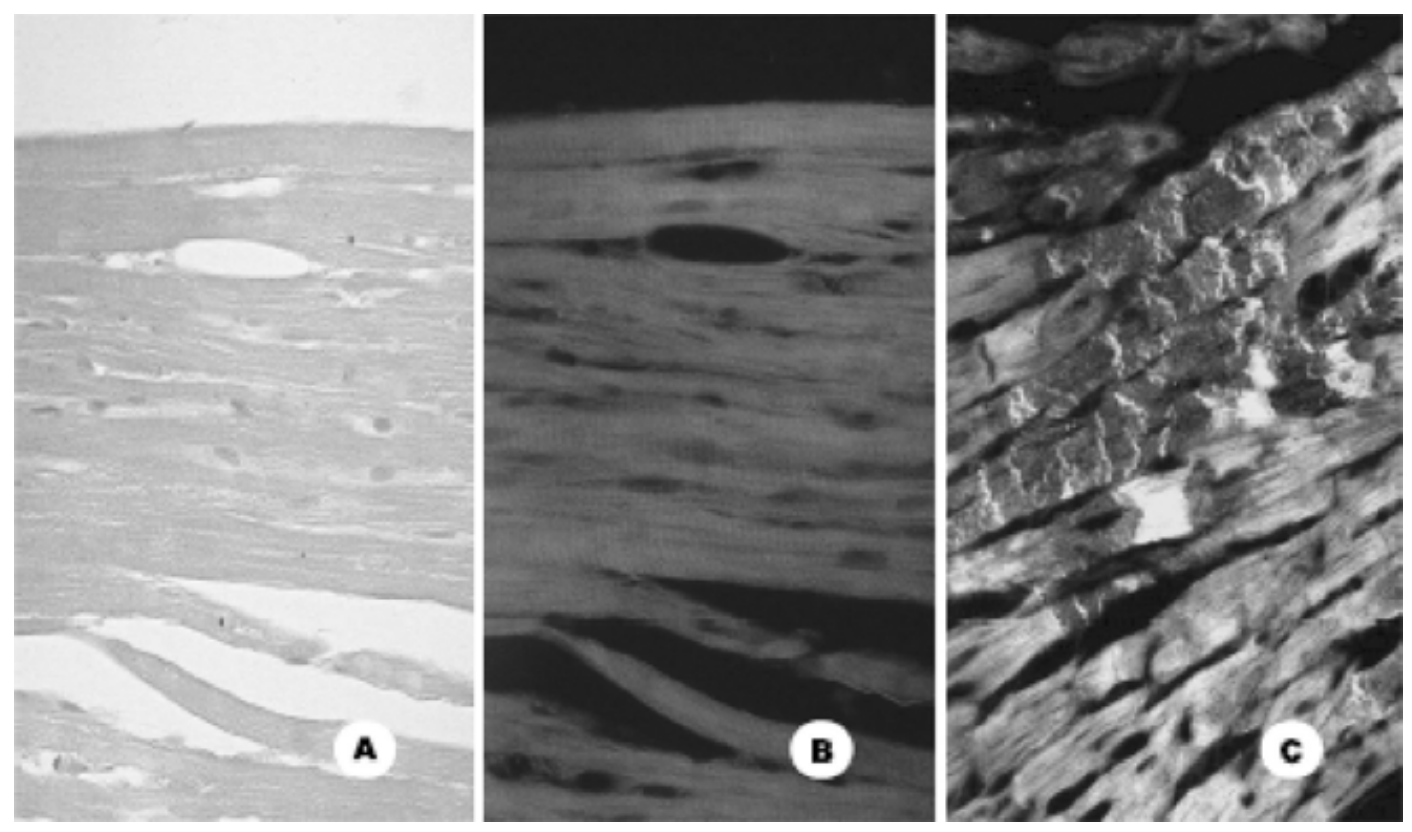

FIG. 3 Histological appearance of rat myocardium from control ( $A$ and $B$ ) and occluded heart (C). Normal histology using H\&E (A) rendered a green autofluorescence under UV light (B), whereas early ischemic changes were identified under fluorescent light microscopy by a typical yellowish autoflorescence (C). Ischemic contraction bands were a common feature. No differences in ischemic changes were observed in hearts from control or treated animals (H\&E, 400x).

\section{Histopathology}

Histopathological evaluation of ischemic damage was done at the end of perfusions in a number of hearts and may indicate the differences induced by exposure accumulated with damage induced by ischemia/reperfusion. No differences in mean severity index (SI: $0=$ no ischemia; $1=<\% ; 2=6-20 \%$; $3=21-35 \% ; 4=36-50 \% ; 5>50 \%$ ) were seen between saline-treated (SI = $2.33 \pm 1.89)$ and $\mathrm{SH}$ rats exposed to PM $(\mathrm{SI}=2.33 \pm 1.53)$ or LPS $(\mathrm{SI}=1.75 \pm$ 1.06). The ischemic damage was most prominent in the left ventricle, more specifically in the free wall than in the septum, but again this was not different between different exposures (Figure 3 ).

\section{Effect of PM Filtrate on $\mathrm{Ca}^{2+}$ Uptake in Cardiomyocytes}

To test whether the effects of in vivo pretreatment on cardiac function were due to a direct effect of soluble components on the heart muscle, as noted previously for aorta (Bagate et al., 2004a, 2004b), we studied Ca uptake in isolated cardiomyocytes. Isolated cardiomyocytes were loaded with fura-2, and uptake of Ca was studied after stimulation with $\mathrm{KCl}$ (receptor independent) or with ATP (receptor dependent). Repetitive (30-min intervals) treatment with $\mathrm{KCl}(50 \mu \mathrm{M})$ or ATP $(100 \mu \mathrm{M})$ led to a reproducible increase in intracellular calcium concentration, mainly from the extracellular compartment (Figure 4). Addition of PM filtrate in concentrations between 1 and $100 \mu \mathrm{g} / \mathrm{ml}$ after the first stimulus 
caused an steady increase in baseline intracellular $\mathrm{Ca}^{2+}$ levels (Figure 5), but also a reduction of $\mathrm{Ca}$ influx by the second stimulus (Figure 5 ). Nifedipine $(2 \mu M)$, a calcium channel antagonist, inhibited the baseline calcium influx elicited by PM $(100 \mu \mathrm{g} / \mathrm{ml}$ ) (Figure 6$)$ as well as that induced by $\mathrm{KCl}$. As a positive control to this experiment, we used the calcium channel agonist BayK $(5 \mu M)$ and found that Nifedipine $(2 \mu M)$ also inhibited BayK-induced Ca uptake in cardiomyocytes (data not shown). The calcium influx upon second stimulation with $\mathrm{KCl}$ or ATP was completely abolished by $\mathrm{Zn}^{2+}$ at $50 \mu M(p<.01$, Figure 5$)$. PM filtrate also caused a decrease of calcium influx by both $\mathrm{KCl}$ and ATP. This effect became significant at a PM filtrate concentration of $100 \mathrm{ug} / \mathrm{ml}(p<.05$ for ATP and $p<$ .01 for $\mathrm{KCl}$, Figure 5).

(a)

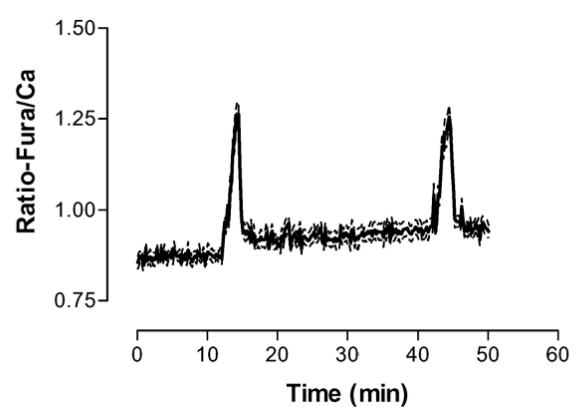

(b)

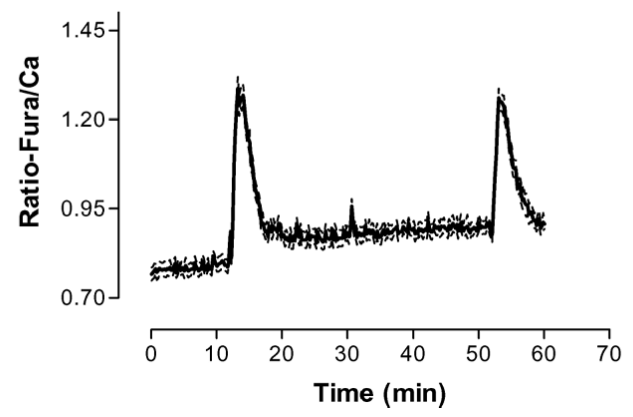

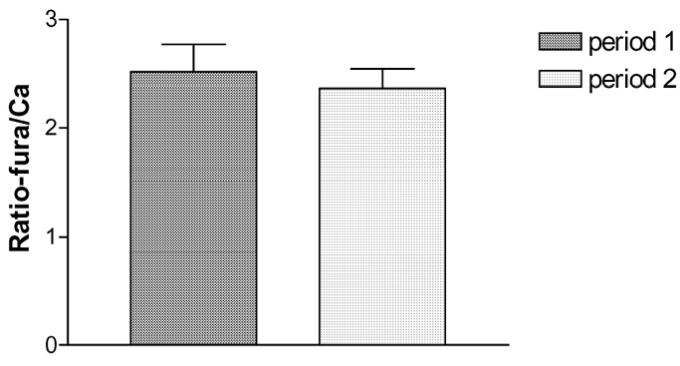

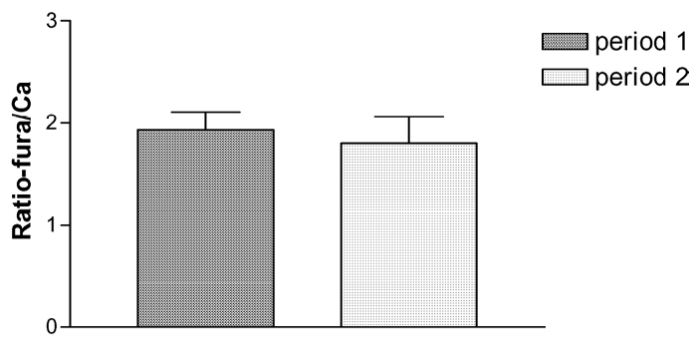

FIG. 4 (A) Receptor-independent and (B) receptor-dependent elicited calcium influx in cardiomyocytes. Cultures of $\mathrm{H} 9 \mathrm{C} 2$ cells were treated at 30-min intervals with $\mathrm{KCl}(50 \mu \mathrm{M})$ or ATP $(100 \mu \mathrm{M})$ and the intracellular Ca concentration was measured by recording the fluorescence as the mean of 7-12 individual cells, shown on the left part of the graph. The right part shows the quantification of results of two subsequent stimulations, given as means \pm SEM of 5-17 individual experiments for each point. Statistical analysis was done by paired student's $t$ test.

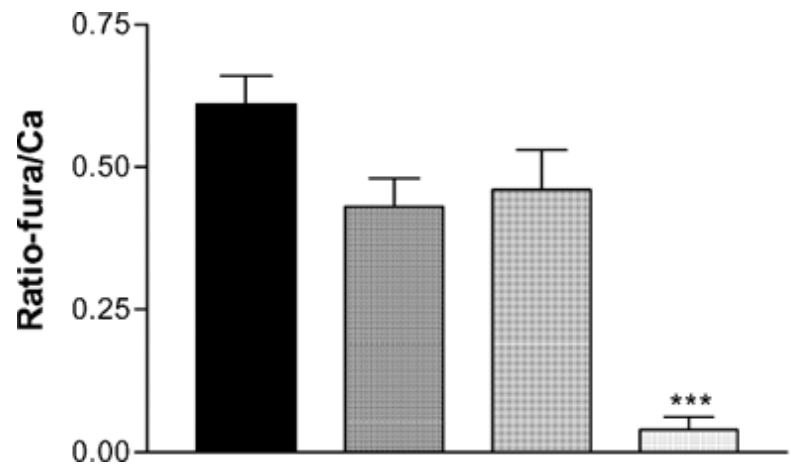

PM $100 \mu \mathrm{g} / \mathrm{ml}$

PM $50 \mu \mathrm{g} / \mathrm{ml}$

$P M 1 \mu \mathrm{g} / \mathrm{ml}$

PM $100 \mu \mathrm{g} / \mathrm{ml}$ vs Nifedipine $2 \mu \mathrm{M}$ 
FIG. 5 PM filtrate and $\mathrm{Zn}^{2+}$ inhibit $\mathrm{KCl}$ - and ATP-induced $\mathrm{Ca}$ increase in cardiomyocytes. The left part of the graph shows typical recordings of repetitive $\mathrm{KCl}$ or ATP additions to cardiomyocytes before (period 1) and after (period 2) addition of PM filtrate $(50-100 \mu \mathrm{g} / \mathrm{ml})$ or $\mathrm{Zn}^{2+}(50 \mu \mathrm{M})$. The right part shows quantification of data from multiple experiments and is given as mean \pm SEM of 5-15 individual experiments for each point. Statistical analysis was done by oneway ANOVA with repeated measures followed by a Student-Newman-Keuls test for multiple comparisons, or paired student's $t$-test. Asterisk indicates significant at $p<.05$; double asterisk, $p<.01$; and triple asterisk, $p<.001$ versus control.
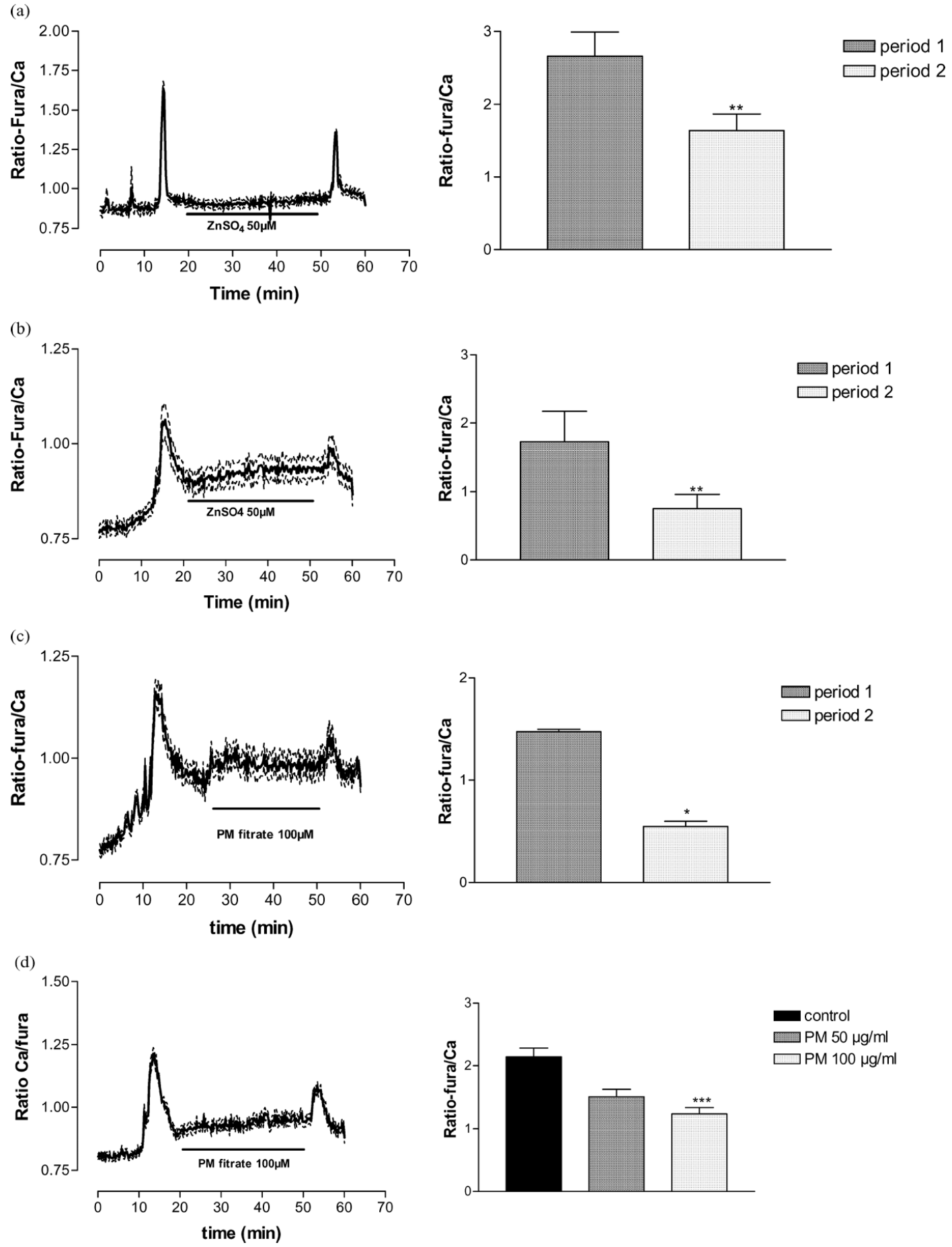
FIG. 6 PM filtrate induces a steady increase of baseline intracellular calcium levels in cardiomyocytes and is inhibited by a Ca channel blocker. Cultures of H9C2 cells were treated with PM at different concentrations and showed a slow increase of intracellular calcium. The addition of nifedipine $(2 \mu M)$ was able to block this baseline increase up to the highest concentration, showing that Ca channels are involved in the inward leaching of Ca. Results are given as means \pm SEM of five to nine individual experiments for each point. Statistical analysis was done by one-way ANOVA with repeated measures followed by a Student- Newman-Keuls test for multiple comparisons. Triple asterisk indicates significance at $p<.001$ versus control.

In order to establish the mode of action of PM, that is, on uptake from the extracellular compartment or blocking of intracellular release, we performed $\mathrm{Ca}$ imaging experiments with the dihydropiridin agonist Bayk 8344 or thapsigargin as an intracellular Ca-ATPase blocker. Two minutes before challenging the cells with thapsigargin, which normally gives an explosive release of intracellular $\mathrm{Ca}$, the medium was replaced with a calcium-free medium supplemented with $1 \mu M$ EGTPA in order to prevent the entrance of extracellular calcium. BayK $(5 \mu M)$ elicited a calcium influx in cardiomyocytes, which was inhibited by PM filtrate at both 1 and $50 \mu \mathrm{g} / \mathrm{ml}(p<.05$ and $p<.01$, respectively, Figure 7, left). In contrast, PM filtrate $(100 \mu \mathrm{g} / \mathrm{ml})$ did not inhibit the calcium influx from the intracellular stores elicited by thapsigargin $(2 \mu M)$ (Figure 7 , right). This shows that calcium channels are affected by components in the PM filtrate and prevent influx from extracellular compartment.
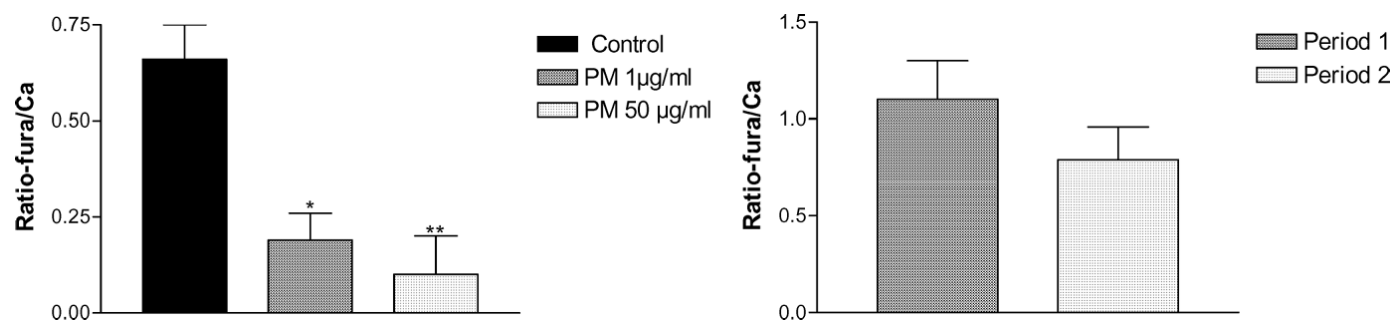

FIG. 7 PM inhibits calcium influx induced by Bayk 8344 in cardiomyocytes. In this experiment BayK $(5 \mu M)$ was used to stimulate intracellular uptake of $\mathrm{Ca}$ and is depicted as control in the left panel. Periods 1 and 2 refer to application of thapsigargin in the absence and in the presence of PM filtrate $(100 \mu \mathrm{g} / \mathrm{ml})$, respectively. Thapsigargin is used to release the intracellular calcium stores. Results are given as means \pm SEM of five to nine individual experiments for each point. Statistical analysis was done by one-way ANOVA with repeated measures followed by a Student-Newman-Keuls test for multiple comparisons, or paired student's $t$-test. Asterisk indicates significance at $p<.05$ and double asterisk at $p$ $<.01$ versus control.

\section{DISCUSSION}

The purpose of this study was to investigate the effect of PM exposure on cardiac function and recovery after ischemia reperfusion injury in SH rats. Our present data showed that pretreatment of SH rats with ambient particles or LPS adversely affects the ability of the isolated heart to recover after an ischemic insult caused by coronary occlusion, although no difference in pathological damage was observed at the end of the experiment. The reduced recovery was mainly seen in LDVP and observed at $4 \mathrm{~h}$ postexposure. We showed that soluble components in the PM preparation and $\mathrm{Zn}$ as the main soluble metal in the PM also elicited a 
depression of LVDP. However other metals may have a similar effect but have not been tested. Additional in vitro studies in cardiomyocytes suggest that the disturbance of cardiac function by PM may be caused by an effect on calcium homeostasis by bioavailable metals to 195pt from PM. However, since LPS induced a strong effect on cardiac recovery, an indirect effect through pulmonary inflammation also may play a significant role.

Heart attacks accompany myocardial ischemic damage, which has been observed in epidemiological studies (Peters et al., 2004). Myocardial ischemia has been implicated in leading to electrical instability and lethal arrhythmia (Ghuran \& Camm, 2001; Brugada, 2001). Myocardial ischemia also leads to loss of cell membrane integrity, which disrupts both depolarization and repolarization, leading to cardiac instability that can cause sudden death in the clinical scenario. We suggested that preexposure to PM may deteriorate the capacity of the heart to recover after myocardial ischemia and used an ex vivo isolated rat heart model using coronary occlusion in ischemia-reperfusion recovery of hearts from preinstilled spontaneously hypertensive rats. SH rats have been used in this study because they are suggested as a model of human with cardiovascular disease and since this subpopulation is a primary group at risk for effect of ambient PM (Pope et al., 2004). SH rats are a suitable animal model for systemic hypertension and underlying cardiac disease, and it has been reported that cardiac effects of PM are stronger in the SH than in the Wistar Kyoto rat (Kodavanti et al., 2000, 2002a).

PM consists of several fractions based on main constituents: for example, the organic fraction, including polyaromatic hydrocarbon (PAHs), the inorganic fraction, including sulfate, nitrate, ammonium, and metals, and the biogenic fraction, which contains essentially bacterial constituents (Dreher, 2000). It is unclear which of the PM constituents are involved in the cardiovascular effects seen in epidemiological studies. Intratracheal instillation of different PM caused PMN influx in rat lung (Bagate et al., 2004a; Kodavanti et al., 2003), and this inflammation was related to the soluble transition metals (Dreher et al., 1997; Kodavanti et al., 2002b). Although the soluble metals seem to play a major role in the effects observed for the heart, current studies do not allow discrimination between an indirect effect of inflammation and a direct effect of bioavailable metals. At the doses used, both PM and LPS instillation elicited similar pulmonary inflammation (Bagate et al., 2004a). The inflammation could induce a release of proinflammatory mediators such as endothelins from the lung, which may be released in the blood and cause impairment of cardiovascular function (Prasad et al., 1991; Nurkiewicz et al., 2006). However, our previous work has demonstrated that lung inflammation based on cellular counts was at a maximum at $24 \mathrm{~h}$ postinstillation (Bagate et al., 2004a), at which time point cardiac effects were no longer present (data not shown). Our previous studies in the same animal model have demonstrated with that intratracheal instillation of $10 \mathrm{mg} / \mathrm{kg}$ PM, plasma concentrations of soluble metals were maximal at $4 \mathrm{~h}$ postinstillation (Bagate et al., 2004a). Interestingly, the reduced recovery from ischemia was also seen at $4 \mathrm{~h}$ but not at $24 \mathrm{~h}$ after instillation. These data suggest that soluble metals could be involved in impairment of cardiac function. This time frame also fits with current epidemiological evidence that shows the strongest relationship between onset of myocardial infarction and exposure to traffic at 1 or $2 \mathrm{~h}$ after exposure (Peters et al., 2004), although traffic-related PM typically contains much less metals. This is an argument to consider the role of the pulmonary inflammation, and is confirmed by the fact that in LPS-pretreated rats also a decrease of LDVP was observed at reperfusion.

The role of soluble metals in cardiovascular effects of PM has been indicated by several studies (Kodavanti et al., 2002a, 2002b, 2003; Bagate et al., 2004a, 2004b). However, the mechanism by which PM and its soluble components elicit a disturbance of cardiac function is not well understood. Calcium is known to play a key role in cardiac contraction and we therefore investigated whether PM can 
induce its cardiac effects through the disturbance of calcium haemostasis. On the one hand, it is still not clear whether the impairment of calcium haemostasis is related to disturbance of intracellular stores or extracellular calcium entrance. The effect of soluble metals on receptor-dependent calcium influx was studied by using ATP-induced $\mathrm{Ca}^{2+}$ influx, which is mediated by purinergic receptors present in cardiomyocytes (Mubagwa \& Flameng, 2001). Both the soluble fraction of PM and $\mathrm{Zn}^{2+}$ inhibited calcium influx elicited by ATP. However, $\mathrm{KCl}$ also induced calcium influx, known to be receptor independent and driven by membrane depolarization, and opening of calcium channels was affected by in vitro exposure to PM filtrate. Our data show an effect of the PM-soluble fraction and of $\mathrm{Zn}^{2+}$, suggesting an effect of soluble metals on calcium channels and ATP receptor channels. We confirmed earlier observations that soluble metals inhibit the calcium entrance from the extracellular medium by using thapsigargin, an inhibitor of calcium ATPase on the endoplasmic reticulum, and Bayk 8443, a dihydropyridine receptor agonist. Both compounds induced a calcium influx, from the intracellular storage and extracellular compartment, respectively. PM filtrate and $\mathrm{Zn}^{2+}$ failed to inhibit intracellular calcium influx elicited by thapsigargin. In contrast, they completely abolished the extracellular calcium influx elicited by the dihydropyridine agonist Bayk 8443.

In summary, our data further contribute to the understanding of how particulate air pollution causes increased cardiovascular morbidity and mortality in individuals suffering from previous myocardial injury (Peters et al., 2004; Pope et al., 2004). Apart from exerting direct effects on the heart, our studies using a high dose of PM in a susceptible animal model provide evidence that recovery from a myocardial ischemia can be decreased after preexposure to PM. The exact mechanism and the nature of the responsible constituent remain an area for further research, but both PM soluble metals and pulmonary inflammation play a role in this process. It remains also open for further study whether this effect also occurs at exposure levels relevant to inhalation.

\section{ACKNOWLEDGEMENT}

The authors acknowledge Dr. Urmila Kodavanti for her independent assessment of cardiac damage using troponin expression. Dr. Abraham Nyska at NIEHS, Research Triangle Park, NC, did the pathology evaluation on the H\&E section. We thank Dr. Wim Vleeming for using his laboratory and equipment to perform the ex vivo studies on rat heart, which were done at the RIVM in Bilthoven. We thank Ton van de Kuil, John F. Boere, Daan Leseman, Jan Bos, and Jan Dormans for their technical assistance in animal studies. We also thank Mrs. Konrad and Mrs. Nanoaweis for their technical assistance in the calcium measurements. Karim Bagaté was a postdoctoral fellow supported by BWPlus 20018, "Systemic effects of particles."

\section{REFERENCES}

Bagate, K., Meiring, J. J., Gerlofs-Nijland, M. E., Vincent, R., Cassee, F. R., and Borm, P. J. A. Vascular effect of ambient particulate matter instillation in spontaneous hypertensive rats. Toxicol. Appl. Pharmacol. (2004a), 197: 29-39.

Bagate, K., Meiring, J. J., Cassee, F. R., and Borm, P. J. A. The effect of particulate matter on resistance and conductance vessels in rat. Inhal. Toxicol. (2004b), 16: 431-436.

Batalha, J. R., Saldiva, P. H., Clarke, R. W., Coull, B. A., Stearns, R. C., Lawrence, J., Murthy, G. G., Koutrakis, P., and Godleski, J. J. Concentrated ambient air particles induce vasoconstriction of small pulmonary arteries in rats. Environ. Health Perspect. (2002), 110: 1191-1197.

Bouthillier, L., Vincent, R., Goegan, P., Adamson, I. Y., Bjarnason, S., Stewart, M., Guenette, J., Potvin, M., and Kumarathasan, P. Acute effects of inhaled urban particles and ozone: Lung morphology, macrophage activity, and plasma endothelin-1. Am. J. Pathol. (1998), 153: 1873-1884. 
Brook, R. D., Brook, J. R., Urch, B., Vincent, R., Rajagopalan, S., and Silverman, F. Inhalation of fine particulate air pollution and ozone causes acute arterial vasoconstriction in healthy adults. Circulation (2002), 105: 1534-1536.

Brugada, P. Residual myocardial ischaemia as a contributor to electrical instability after myocardial infarction. Eur. Heart J. (2001), 22: 1845-1846.

Dockery, D. W., Pope, C. A., 3rd, Xu, X., Spengler, J. D., Ware, J. H., Fay, M. E., Ferris, B. G., Jr., and Speizer, F. E. An association between air pollution and mortality in six U.S. cities. N. Engl. J. Med. (1993), 329: 1753-1759.

Dreher, K. L. Particulate matter physicochemistry and toxicology: In search of causality-A critical perspective. Inhal. Toxicol. (2000), 12: 45-57.

Dreher, K. L., Jaskot, R. H., Lehmann, J. R., Richards, J. H., McGee, J. K., Ghio, A. J., and Costa, D. L. Soluble transition metals mediate residual oil fly ash-induced acute lung injury. J. Toxicol. Environ. Health (1997), 50: 285-305.

Ghuran, A. V., and Camm, A. J. Ischaemic heart disease presenting as arrhythmias. Br. Med. Bull. (2001), 59: 193-210.

Godleski, J. J., Verrier, R. L., Koutrakis, P., Catalano, P., Coull, B., Reinisch, U., Lovett, E. G., Lawrence, J., Murthy, G. G., Wolfson, J. M., Clarke, R. W., Nearing, B. D., and Killingsworth, C. Mechanisms of morbidity and mortality from exposure to ambient air particles. Res. Rep. Health Effects Inst. (2000), 9: 5-88.

Gold, D. R., Litonjua, A., Schwartz, J., Lovett, E., Larson, A., Nearing, B., Allen, G., Verrier, M., Cherry, R., and Verrier, R. Ambient pollution and heart rate variability. Circulation (2000), 101: 12671273.

Hearse, D. J., Erol, C., Robinson, L. A., Maxwell, M. P., and Braimbridge, M. V. Particle induced coronary vasoconstriction during cardioplegic infusion. Characterization and possible mechanisms. J. Thorac. Cardiovasc. Surg. (1985), 89: 428-438.

Knaapen, A. M., den Hartog, G. J., Bast, A., and Borm, P. J. Ambient particulate matter induces relaxation of rat aortic rings in vitro. Hum. Exp. Toxicol. (2001), 20: 259-265.

Kodavanti, U. P., Schladweiler, M. C., Ledbetter, A. D., Watkinson, W. P., Campen, M. J., Winsett, D. W., Richards, J. R., Crissman, K. M., Hatch, G. E., and Costa, D. L. The spontaneously hypertensive rat as a model of human cardiovascular disease: Evidence of exacerbated cardiopulmonary injury and oxidative stress from inhaled emission particulate matter. Toxicol. Appl. Pharmacol. (2000), 164: 250-263.

Kodavanti, U. P., Schladweiler, M. C., Ledbetter, A. D., Hauser, R., Christiani, D. C., McGee, J., Richards, J. R., and Costa, D. L. Temporal association between pulmonary and systemic effects of particulate matter in healthy and cardiovascular compromised rats. J. Toxicol. Environ. Health A (2002a), 65: 1545-1569.

Kodavanti, U. P., Schladweiler, M. C., Ledbetter, A. D., Hauser, R., Christiani, D. C., Samet, J. M. McGee, J., Richards, J. H., and Costa, D. L. Pulmonary and systemic effects of zinc-containing emission particles in three rat strains: Multiple exposure scenarios. Toxicol. Sci. (2002b), 70: 73-85.

Kodavanti, U. P., Moyer, C. F., Ledbetter, A. D., Schladweiler, M. C., Costa, D. L., Hauser, R., Christiani, D. C., and Nyska, A. Inhaled environmental combustion particles cause myocardial injury in the Wistar Kyoto rat. Toxicol. Sci. (2003), 71: 237-245.

Meiring, J. J., Borm, P. J., Bagate, K., Semmler, M., Seitz, J., Takenaka, S., and Kreyling, W. G. The influence of hydrogen peroxide and histamine on lung permeability and translocation of iridium nanoparticles in the isolated perfused rat lung. Part. Fibre Toxicol. (2005), 2: 3.

Mills, N. L., Tornqvist, H., Robinson, S. D., Gonzalez, M., Darnley, K., MacNee, W., Boon, N. A., Donaldson, K., Blomberg, A., Sandstrom, T., and Newby, D. E. Diesel exhaust inhalation causes vascular dysfunction and impaired endogenous fibrinolysis. Circulation (2005), 112(25): 3930-3936.

Minami, M., Endo, T., Hamaue, N., Hirafuji, M., Mori, Y., Hayashi, H., Sagai, M., and Suzuki, A. K. Electrocardiographic changes induced by diesel exhaust particles (DEP) in guinea pigs. Res. Commun. Mol. Pathol. Pharmacol. (1999), 105: 67-76.

Mubagwa, K., and Flameng, W. Adenosine, adenosine receptors and myocardial protection: An updated overview. Cardiovasc. Res. (2001), 52(1): 25-39.

Nemmar, A., Nemery, B., Hoet, P. H., Vermylen, J., and Hoylaerts, M. F. Pulmonary inflammation and thrombogenicity caused by diesel particles in hamsters: role of histamine. Am. J. Respir. Crit. Care Med. (2003), 168: 1366-1372.

Nurkiewicz, T. R., Porter, D. W., Barger, M., Millecchia, L., Rao, K. M., Marvar, P. J., Hubbs, A. F., Castranova, V., and Boegehold, M. A. Systemic microvascular dysfunction and inflammation after pulmonary particulate matter exposure. Environ. Health Perspect. (2006), 114(3): 412-419. 
Osornio, A. R., and Ossa Gómez, L. J. Diagnóstico histológico temprano del infarto del miocardio por autofluorescencia. Una evaluación en humanos y en animales de experimentación. Arch. Inst. Cardiol. Méx. (1983), 53: 477-483.

Pacher, P., Csordas, P., Schneider, T., and Hajnoczky, G. Quantification of calcium signal transmission from sarco-endoplasmic reticulum to the mitochondria. J. Physiol. (2000), 3: 553-564.

Pacher, P., Csordas, G., and Hajnoczky, G. Mitochondrial ca(2+) signaling and cardiac apoptosis. BioSignals. Recept. (2001), 10: 200-223.

Peters, A., Perz, S., Doring, A., Stieber, J., Koenig, W., and Wichmann, H. E. Increases in heart rate during an air pollution episode. Am. J. Epidemiol. (1999), 150: 1094-1098.

Peters, A., von Klot, S., Heier, M., Trentinaglia, I., Hormann, A., Wichmann, H. E., and Lowel, H. Cooperative Health Research in the Region of Augsburg Study Group. Exposure to traffic and the onset of myocardial infarction. N. Engl. J. Med. (2004), 351(17): 1721-1730.

Pope, C. A., III, Verrier, R. L., Lovett, E. G., Larson, A. C., Raizenne, M. E., Kanner, R. E., Schwartz, J., Villegas, G. M., Gold, D. R., and Dockery, D. W. Heart rate variability associated with particulate air pollution. Am. Heart J. (1999), 138: 890-899.

Pope, C. A., 3rd, Burnett, R. T., Thurston, G. D., Thun, M. J., Calle, E. E., Krewski, D., and Godleski, J. J. Cardiovascular mortality and long-term exposure to particulate air pollution: epidemiological evidence of general pathophysiological pathways of disease. Circulation (2004), 109: 71-77.

Prasad, K., Lee, P., and Kalra, J. Influence of endothelin on cardiovascular function, oxygen free radicals, and blood chemistry. Am. Heart J. (1991), 121: 178-187.

Sakakibara, M., Minami, M., Endo, T., Hirafuji, M., Murakami, S., Mori, Y., and Sagai, M. Biological effects of diesel exhaust particles (DEP) on isolated cardiac muscle of guinea pigs. Res. Commun. Mol. Pathol. Pharmacol. (1994), 86: 99-110.

Samet, J. M., Ghio, A. J., Costa, D. L., and Madden, M. C. Increased expression of cyclooxygenase 2 mediates oil fly ash-induced lung injury. Exp. Lung Res. (2000), 26: 57-69 .

Schins, R. P., Lightbody, J. H., Borm, P. J., Shi, T., Donaldson, K., and Stone, V. Inflammatory effects of coarse and fine particulate matter in relation to chemical and biological constituents. Toxicol. Appl. Pharmacol. (2004), 195(1): 1-11.

Seaton, A., MacNee, W., Donaldson, K., and Godden, D. Particulate air pollution and acute health effects. Lancet (1995), 345: 176-178.

Szalai, G., Csordas, G., Hantash, B. M., Thomas, A. P., and Hajnoczky, G. Calcium signal transmission between ryanodine receptors and mitochondrial. J. Bio. Chem. (2000), 275: 15305-15313.

Van Eeden, S. F., Tan, W. C., Suwa, T., Mukae, H., Terashima, T., Fujii, T., Qui, D., Vincent, R., and Hogg, J. C. Cytokines involved in the systemic inflammatory response induced by exposure to particulate matter air pollutants (PM(10)). Am. J. Respir. Crit. Care Med. (2001), 164: 826-830

$\mathrm{Xu}, \mathrm{H}$. , Lin, I., and Yuan, W. J. Antiarrhythmic effect of endothelin-A receptor antagonist on acute ischemic arrhythmia in isolated rat heart. Acta Pharmacol. Sin. (2003), 24: 37-44.

Vincent, R., Kumurathasan, P., Goegan, P., Bjarnason, S. G., Guenette, J., Bertube, D., Adamason, I. Y., Desjardins, S., Burnett, R. T., Miller, F. J., and Battistini, B. Inhalation toxicology of urban ambient particulate matter: Acute cardiovascular effects in rats. Res. Rep. Health Effects Inst. (2001), 104: 562. 